\title{
Predictors of Habitual and Addictive Smartphone Behavior in Problematic Smartphone Use
}

\author{
Jihwan Park', Jo-Eun Jeong ${ }^{2}$, and Mi Jung Rho' ${ }^{凶}$ \\ 'Department of Urology, Seoul St. Mary's Hospital, College of Medicine, The Catholic University of Korea, Seoul, Republic of Korea \\ 2Department of Psychiatry, Daejeon St. Mary's Hospital, College of Medicine, The Catholic University of Korea, Seoul, Republic of Korea
}

Objective Smartphones have become common, and problematic smartphone use (PSU) is increasing. Predictors of PSU should be identified to prevent it. Little is known about the role of content types of smartphone use as predictors of PSU. Therefore, we aimed to evaluate the predictors of two proposed concepts of PSU, namely habitual smartphone behavior (SB) and addictive SB, within the context of the application (app) categories.

Methods We studied 1,039 smartphone users using online surveys conducted between January 2 and 31, 2019. We employed multiple regression analysis to identify the predictors of habitual and addictive SB. We controlled for sex and age (mean=39.20).

Results Common predictors of habitual and addictive SB were the use of social networking services, games, entertainment apps, and average weekend smartphone usage time. The predictors of habitual SB were the use of web and lifestyle apps, weekly usage frequency, and sex (female) and the predictors of addictive SB were the use of shopping apps and sleep duration.

Conclusion This study revealed the need to consider habitual and addictive SB in evaluating PSU. The predictors in terms of the content types of smartphone usage can be used to develop monitoring and prevention services for PSU.

Psychiatry Investig 2021;18(2):118-125

Key Words Problematic smartphone use, Habitual smartphone behavior, Addictive smartphone behavior, Smartphone usage time, Sleep duration, Application category.

\section{INTRODUCTION}

Smartphones have become a common feature around the world and an essential part of our daily lives. This global popularity has raised concerns about its negative effects associated with problematic smartphone use (PSU). Scholars define PSU as compulsive and maladaptive smartphone behavior. ${ }^{1}$ In South Korea, $20.0 \%$ of the people are included in the PSU group according to the smartphone overdependence scale, which measures the self-control failure, salience, and serious consequences of smartphone use. ${ }^{2}$ Furthermore, the proportion of PSU in preschoolers (3-9 years old) and the elderly (aged 60 or older) is steadily increasing. ${ }^{2}$ Therefore, it is important to identify the

Received: July 27, 2020 Revised: November 20, 2020

Accepted: December 4, 2020

$\triangle$ Correspondence: Mi Jung Rho, $\mathrm{PhD}$

Department of Urology, Seoul St. Mary's Hospital, College of Medicine, The Catholic University of Korea, 222 Banpo-daero, Seocho-gu, Seoul 06591, Republic of Korea

Tel: +82-2-2258-5905, Fax: +82-2-537-8233, E-mail: rhomijung@gmail.com

(a) This is an Open Access article distributed under the terms of the Creative Commons Attribution Non-Commercial License (https://creativecommons.org/licenses/bync/4.0) which permits unrestricted non-commercial use, distribution, and reproduction in any medium, provided the original work is properly cited. predictors or risk factors to prevent PSU.

Van Deursen et al. ${ }^{3}$ proposed two concepts in PSU, namely habitual smartphone behavior (SB) and addictive SB. Habitual SB means repetitive smartphone use without self-instruction or conscious thinking, such as automatically checking a smartphone. Oulasvirta et al. ${ }^{4}$ reported that the increased habit formation of checking a smartphone for message notification led to an increase in PSU. Addictive SB, a similar concept in smartphone addiction, assumes intensive smartphone use and failure to control the behavior despite significant harmful consequences. As a basic conception, a habit is something that we do regularly and that develops over time with repetition and the repetition may be unconscious. ${ }^{5}$ Addiction can appear as a habit in that it involves repetitive behaviors, but addiction is a more complex activity and involves physiological response such as withdrawal symptoms. ${ }^{6,7}$ In terms of biological perspectives, habits rely primarily on the cortico-striatal-thalamic circuitry (CSTC) and allow the behavior to be engaged without involving the prefrontal cognitive circuitry. ${ }^{5,8}$ However, if habitual behavior begins to lead to unfavorable results, prefrontal executive processing can impose correcting or stopping the 
behavior. ${ }^{9}$ However, addiction is characterized by an inability to cognitively regulate behavior, while a habit is more choicebased. ${ }^{6,7}$ Thus, even when presented with negative consequences, the addictive behaviors will continue. The development of an addiction may result from a decrease in executive control over behavior and/or a strengthening of CSTC. 6 These two concepts have both commonalities and differences. Therefore, it is necessary to consider both the habitual and addictive SB aspects to evaluate more specific predictors of PSU. However, no research has been conducted yet that predicts and distinguishes habitual and addictive SB in smartphone use.

Previous studies have evaluated psychological predictors such as low self-esteem, depressive symptoms, ${ }^{10}$ interpersonal anxiety, ${ }^{10}$ low self-control, ${ }^{10,11}$ and impulsivity ${ }^{12}$ in PSU. Recent studies have also examined the types of smartphone usage such as social use [e.g., social networking service (SNS) ${ }^{13}$ and nonsocial use (e.g., browsing the Internet for news or entertainment). ${ }^{3,14}$ With regard to types of smartphone use, some studies found that social media use was related to PSU, ${ }^{13}$ while others reported that non-social smartphone use was more strongly associated with PSU., ${ }^{3,14}$ However, little is known about the specific types of smartphone usage, especially in habitual and addictive SB.

Therefore, we aimed to find out the predictors of habitual and addictive SB in relation to the role of content types of smartphone use based on application (app) usage behavior.

\section{METHODS}

\section{Participants}

We received smartphone users' survey data from a polling company between January 2 and January 31, 2019. The polling company was dataSpring. The company has Korean online panel with 379,451 people (https://www.d8aspring.com/asiansample) (as of January 2020). The company sent mail, including an online survey link, and an informed consent link to an online panel and all participants completed anonymous webbased questionnaires. The inclusion criteria were that participants should be smartphone users and adults in their 20s to 50s. Respondents with the same answer, meaningless short answer responders (e.g., $\wedge \wedge,{ }^{\star} \& \wedge \&$, etc.), and logical error responders were excluded from the study. In addition, we regarded the responses of those who responded faster than the minimum expected time as meaningless responses; therefore, we also excluded them. Finally, 1,039 smartphone users were included in the analyses.

\section{Ethics}

The study was conducted in accordance with the Declaration of Helsinki and was approved by the Institutional Review
Board of Catholic University (IRB number: MC18QNSI0101).

\section{Measures and procedure}

This study used 14 variables: two dependent variables, 10 independent variables, and two control variables. Furthermore, it used a multiple regression analysis to identify the predictors of habitual and addictive SB (Figure 1).

We used habitual SB and addictive SB as dependent variables. Habitual smartphone usage was measured using an instrument adapted from Limayem et al. ${ }^{15}$ The original scale was developed for habitual Internet use, which the previous study adapted to the use of smartphones, and had shown a high internal consistency (Cronbach's $\alpha=0.92){ }^{3}$ The modified scale for habitual SB consisted of six items with a five-point Likert scale from 1 (never) to 5 (always). The total score was from 6 to 30. Higher scores indicated greater habitual SB.

Addictive smartphone usage was measured using the modified version 3 of the mobile phone problem use scale developed by Bianchi and Phillips. ${ }^{16}$ This modified scale consists of 26 items covering addictive features of smartphone use such as tolerance, withdrawal, craving, escape from problems, social motivation, and negative consequence had good internal consistency (Cronbach's $\alpha=0.93$ ). ${ }^{3}$ In an original scale, addictive smartphone behavior consisted of 26 items measured using a ten-point Likert scale. However, we used a five-point Likert scale from 1 (never) to 5 (always) to make the response easier. Therefore, the total score was from 26 to 130. Higher scores indicated addictive SB.

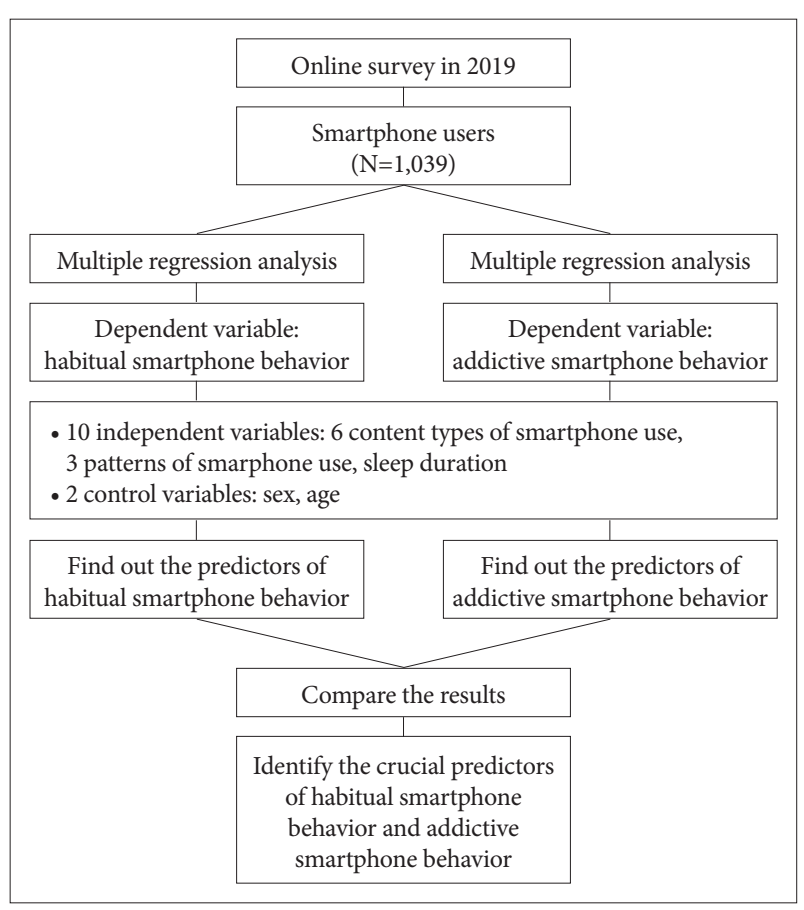

Figure 1. Research process. 
Nine variables related to smartphone usage and sleep duration were used as independent variables. These were three smartphone usage patterns (weekday smartphone usage time, weekend smartphone usage time, and weekly frequency of smartphone use) and six content types of smartphone use according to the apps (SNS/Chatting, web, games, entertainment, shopping, and lifestyle) (Table 1). The types of smartphone use included 16 classified items: finance, systems, web, SNS/chatting, shopping, business, tools/productivity, entertainment, weather, transportation, photos, lifestyle, health/exercise, games, education, and decoration. ${ }^{17}$ Among the 16 items, two researchers and one psychiatrist chose the six smartphone app categories based on the apps that are mostly used.

The SNS/Chatting apps are mainly used for seeking social relationships and consist of social networks, messengers, chatting, and vlogs. The web apps are primarily used for seeking information and consist of web browsers such as Naver, Google, Chrome, Daum, Nate, and Dolphin. The game apps are for game enjoyment such as simulation games, role-playing games, arcade games, action games, board games, game money, and game items. Entertainment apps are apps that have diverse content for enjoyment, such as media/videos, sports, travel, music, books, and comics. Shopping apps are mainly for consumption and buying purposes and consist of clothes, tickets, books, and used items. Finally, lifestyle apps are predominantly for ordinary life maintenance such as phone calls, text messages, e-mails, addresses, diaries, deliveries, and delivery tracking. Each item in the perceptions of app uses consisted of a fivepoint Likert scale from 1 (never) to 5 (always).

We also included sleep duration as an independent variable because lack of sleep and sleep disturbance was found to positively correlate with PSU and Internet addiction in previous studies. ${ }^{18-20}$ Other studies also showed that smartphone addiction correlates with sleep quality. ${ }^{21-23}$ A previous study even observed whether the phone screens of users are on/off to detect sleep duration. ${ }^{24}$ In addition, sleep disturbances have been reported to be associated with various mental conditions. ${ }^{25,26}$ Accordingly, we thought that sleep duration might be an important factor and should be considered as an inde- pendent variable in PSU.

Finally, we controlled for sex and age to focus on the 10 variables as mentioned above because previous studies indicated that women and young people engage in PSU more than men and elderly people do..$^{11,27}$

\section{Statistical analysis}

We conducted a multiple regression analysis on 1,039 smartphone users using R (version 3.5.0). Among the variable selection methods, we used the "enter" method for inputting independent variables.

\section{RESULTS}

\section{Participants' characteristics}

As shown in Table 2, 50\% of the respondents were male. The respondents' ages were evenly distributed from 20 s to $50 \mathrm{~s}$. In terms of marital status, $54.1 \%$ of the respondents were married or living with a partner. Most (66.9\%) of the respondents belonged to the group consisting of office workers, administrative professionals, service industry professionals, professional technicians, freelancers, and production employees. The monthly income of $57.5 \%$ of the respondents was over $\$ 3,584.23$. In addition, $63.2 \%$ of the respondents lived in the capital city and 82.9\% had Android phones.

\section{Predicting factors of the habitual and addictive SB}

Table 3 and Figure 2 show the results of the multiple regression analysis to identify the predictors of habitual and addictive SB.

We found the following to be the predictors of habitual SB. The app usages for entertainment $(t=5.493, \mathrm{p} \leq 0.001)$, SNS/ chatting ( $\mathrm{t}=4.983, \mathrm{p} \leq 0.001)$, web $(\mathrm{t}=4.868, \mathrm{p} \leq 0.001)$, lifestyle $(\mathrm{t}=4.128, \mathrm{p} \leq 0.001)$, and games $(\mathrm{t}=2.712, \mathrm{p}=0.007)$ were significantly associated with habitual SB. In addition, weekly usage frequency $(\mathrm{t}=3.041, \mathrm{p}=0.002)$, average weekend smartphone usage time ( $\mathrm{t}=2.169, \mathrm{p}=0.030)$, and sex (female) $(\mathrm{t}=2.885, \mathrm{p}=$ $0.004)$ were significantly associated with habitual $\mathrm{SB}(\mathrm{F}=35.601$, $\mathrm{p} \leq 0.001)$. According to the standardized coefficients repre-

Table 1. Six smartphone app categories

\begin{tabular}{lll}
\hline \multicolumn{1}{c}{ Category } & \multicolumn{1}{c}{ Purpose of use } & \multicolumn{1}{c}{ Applications } \\
\hline SNS/chatting & Social relationship seeking & Social networks, messengers, chatting, and vlogs \\
Web & Information seeking & Naver, Google, Chrome, Daum, Nate, and Dolphin \\
Game & Game enjoyment & $\begin{array}{c}\text { Simulation games, role-playing games, arcade games, action games, board games, } \\
\text { game money, and game items }\end{array}$ \\
Entertainment & Content enjoyment & Media/videos, sports, travel, music, books, and comics \\
Shopping & Consumption seeking and buying & Clothes, tickets, books, and used items \\
Lifestyle & Ordinary life maintenance & Phone calls, text messages, e-mails, addresses, diaries, deliveries, and delivery tracking \\
\hline
\end{tabular}


Table 2. Demographic characteristics

\begin{tabular}{|c|c|c|}
\hline Variables & $\mathrm{N}$ & Percentage \\
\hline \multicolumn{3}{|l|}{ Sex } \\
\hline Male & 520 & 50.0 \\
\hline Female & 519 & 50.0 \\
\hline \multicolumn{3}{|l|}{ Age $($ mean=39.20) } \\
\hline $20-29$ years & 258 & 24.8 \\
\hline $30-39$ years & 261 & 25.1 \\
\hline $40-49$ years & 263 & 25.3 \\
\hline $50-59$ years & 257 & 24.8 \\
\hline \multicolumn{3}{|l|}{ Marital status } \\
\hline Single* & 477 & 45.9 \\
\hline Married or living with a partner & 562 & 54.1 \\
\hline \multicolumn{3}{|l|}{ Occupation } \\
\hline Office worker, etc. ${ }^{\dagger}$ & 695 & 66.9 \\
\hline Student & 165 & 15.9 \\
\hline Housewife, unemployed and other & 179 & 17.2 \\
\hline \multicolumn{3}{|l|}{ Monthly income } \\
\hline Under $\$ 1,792.11$ & 111 & 10.7 \\
\hline$\$ 1,792.11-\$ 3,584.23$ & 331 & 31.8 \\
\hline$\$ 3,584.23-\$ 5,376.34$ & 354 & 34.1 \\
\hline Over $\$ 5,376.34$ & 243 & 23.4 \\
\hline \multicolumn{3}{|l|}{ Residential area } \\
\hline Capital area (including Seoul) & 657 & 63.2 \\
\hline Noncapital area & 382 & 36.8 \\
\hline \multicolumn{3}{|l|}{ Smartphone device type } \\
\hline Android & 861 & 82.9 \\
\hline Apple iOS & 178 & 17.1 \\
\hline Total & 1,039 & 100.0 \\
\hline
\end{tabular}

The exchange rate for the Korean won to the U.S. dollar is $1,116.00$ won (buy and sell base rate on January 31, 2019). *single: never married, divorced, separated, or widowed, ${ }^{\dagger}$ office worker, etc.: office worker, administrative professional, service industry professional, professional technician, freelancer, or production employee

senting the relative contribution of the independent variables, entertainment apps had the greatest effect on habitual SB $(\beta=$ 0.178 ), followed by web apps ( $\beta=0.158)$, SNS/chatting apps $(\beta=0.150)$, lifestyle apps $(\beta=0.132)$, average weekend smartphone usage time ( $\beta=0.088)$, weekly usage frequency $(\beta=0.082)$, sex (female) $(\beta=0.080)$, and game apps $(\beta=0.077)$. The coefficient of determination $\left(\mathrm{R}^{2}\right)$ for this model was 0.294 , indicating that $29.4 \%$ of the variation in habitual SB can be explained by these eight independent variables.

The following were found to be the predictors of addictive SB. The usage of game $(t=7.719, p \leq 0.001)$, shopping $(t=5.369$, $\mathrm{p} \leq 0.001)$, entertainment $(\mathrm{t}=2.991, \mathrm{p}=0.003)$, and SNS/chatting apps $(t=2.895, p=0.004)$, average weekend smartphone usage time $(\mathrm{t}=2.072, \mathrm{p}=0.039)$, and sleep duration $(\mathrm{t}=-2.919, \mathrm{p}=0.004)$ were significantly associated with addictive $\mathrm{SB}(\mathrm{F}=19.450, \mathrm{p} \leq$ $0.001)$. Game apps had the greatest effect on addictive $\mathrm{SB}(\beta=$ $0.235)$, followed by shopping apps $(\beta=0.186)$, entertainment apps ( $\beta=0.104)$, SNS/chatting apps ( $\beta=0.094)$, average weekend smartphone usage time $(\beta=0.090)$, and sleep duration $(\beta=$ $-0.083)$. The coefficient of determination $\left(R^{2}\right)$ for this model was 0.185 , indicating that 18.5 percent of the variation in addictive $\mathrm{SB}$ can be explained by these five independent variables.

The predictors that were common for both habitual and addictive SB were the use of SNS, game, and entertainment apps and average weekend smartphone usage time. The predictors of habitual SB, which were not predictors of addictive SB, were the use of web and lifestyle apps, weekly usage frequency, and sex (female), while the predictors of addictive SB, which were not predictors of habitual SB, were the use of shopping apps and sleep duration.

\section{DISCUSSION}

In the present study, we identified the predictors of the two concepts of PSU, namely habitual and addictive SB, especially in relation to the content types of apps, smartphone usage pattern, and sleep duration.

First, we identified the common predictors of habitual and addictive SB.

The predictors that were common for both habitual and addictive SB were the use of SNS, games, and entertainment apps according to the content types of the apps. In other words, the problematic use of the SNS, game, and entertainment contents may have characteristics of both habitual and addictive $\mathrm{SB}$. In the aspect of addictive usage, previous studies reported that SNS, game, and entertainment contents tend to be addictive ${ }^{28-31}$ and their uses were positive predictors of smartphone addiction according to the media content types. ${ }^{32,33}$ In our study, among the three content types, the use of game apps had a greater influence on addictive SB than on habitual SB (t-value of addictive and habitual $\mathrm{SB}=7.719$ and 2.712 , respectively). Past studies demonstrated that online game attraction and online game use were significant predictors of Internet addiction - one of the other technological addictions. ${ }^{34-36}$ These might suggest that smartphones are gradually replacing desktops in the use of these content types. In the aspect of habitual usage, although the uses of all three content types were predictors of habitual SB, the use of SNS and entertainment apps had a greater influence on habitual SB than on addictive SB. The SNS app category consists of social networks, messengers, chatting, and vlogs and the entertainment app category consists of comics, media/videos, sports, travel, music, and books. These categories are closely related to the most popular apps such as 
Table 3. Multiple regression analysis results

\begin{tabular}{|c|c|c|c|c|c|c|c|c|c|c|}
\hline \multirow{3}{*}{$\begin{array}{l}\text { Dependent } \\
\text { variables } \\
\text { variables }\end{array}$} & \multicolumn{5}{|c|}{$\begin{array}{c}\text { Habitual SB } \\
\text { (mean: 22.41, range: 6-30, Cronbach's } \alpha=0.860 \text { ) }\end{array}$} & \multicolumn{5}{|c|}{$\begin{array}{c}\text { Addictive SB } \\
\text { (mean: } 65.72 \text {, range: } 26-130, \text { Cronbach's } \alpha=0.946 \text { ) }\end{array}$} \\
\hline & \multicolumn{2}{|c|}{$\begin{array}{l}\text { Nonstandardized } \\
\text { coefficients }\end{array}$} & \multirow{2}{*}{$\begin{array}{c}\begin{array}{c}\text { Standardized } \\
\text { coefficients }\end{array} \\
\beta\end{array}$} & \multirow[t]{2}{*}{$\mathrm{t}$ value } & \multirow[t]{2}{*}{ Sig. } & \multicolumn{2}{|c|}{$\begin{array}{l}\text { Nonstandardized } \\
\text { coefficients }\end{array}$} & \multirow{2}{*}{$\begin{array}{c}\begin{array}{c}\text { Standardized } \\
\text { coefficients }\end{array} \\
\beta\end{array}$} & \multirow[t]{2}{*}{$\mathrm{t}$ value } & \multirow[t]{2}{*}{ Sig. } \\
\hline & $\mathrm{B}$ & SE & & & & B & SE & & & \\
\hline (Constant) & 11.945 & 0.822 & - & 14.531 & $<0.000^{\ddagger}$ & 43.073 & 3.872 & & 11.125 & $<0.000^{\ddagger}$ \\
\hline \multicolumn{11}{|l|}{ App category } \\
\hline SNS/chatting & 0.548 & 0.110 & 0.150 & 4.983 & $<0.000^{\ddagger}$ & 1.500 & 0.518 & 0.094 & 2.895 & $<0.004^{\dagger}$ \\
\hline Games & 0.235 & 0.087 & 0.077 & 2.712 & $<0.007^{\dagger}$ & 3.153 & 0.408 & 0.235 & 7.719 & $<0.000^{\ddagger}$ \\
\hline Entertainment & 0.706 & 0.129 & 0.178 & 5.493 & $<0.000^{\ddagger}$ & 1.810 & 0.605 & 0.104 & 2.991 & $0.003^{\dagger}$ \\
\hline Web & 0.709 & 0.146 & 0.158 & 4.868 & $<0.000^{\ddagger}$ & -0.426 & 0.686 & -0.022 & -0.621 & 0.535 \\
\hline Lifestyle & 0.556 & 0.135 & 0.132 & 4.128 & $<0.000^{\ddagger}$ & -0.727 & 0.635 & -0.039 & -1.145 & 0.252 \\
\hline Shopping & 0.027 & 0.125 & 0.007 & 0.217 & 0.829 & 3.165 & 0.589 & 0.186 & 5.369 & $<0.000^{\ddagger}$ \\
\hline Sleep duration & -0.002 & 0.001 & -0.038 & -1.442 & 0.150 & -0.017 & 0.006 & -0.083 & -2.919 & $0.004^{\dagger}$ \\
\hline $\begin{array}{l}\text { Weekly usage } \\
\text { frequency }\end{array}$ & 0.002 & 0.001 & 0.082 & 3.041 & $0.002^{\dagger}$ & 0.003 & 0.004 & 0.024 & 0.814 & 0.416 \\
\hline $\begin{array}{l}\text { Average weekend } \\
\text { smartphone usage time }\end{array}$ & 0.002 & 0.001 & 0.088 & 2.169 & $0.030^{*}$ & 0.007 & 0.003 & 0.090 & 2.072 & $0.039^{*}$ \\
\hline $\begin{array}{l}\text { Average weekday smartphone } \\
\text { usage time }\end{array}$ & 0.000 & 0.001 & 0.000 & -0.001 & 0.999 & 0.000 & 0.003 & 0.001 & 0.026 & 0.979 \\
\hline Sex (0:male, 1 :female) & 0.662 & 0.230 & 0.080 & 2.885 & $0.004^{\dagger}$ & -1.657 & 1.082 & -0.046 & -1.532 & 0.126 \\
\hline Age & 0.117 & 0.107 & 0.032 & 1.093 & 0.275 & 0.790 & 0.502 & 0.049 & 1.573 & 0.116 \\
\hline
\end{tabular}

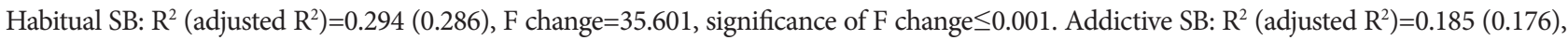
$\mathrm{F}$ change $=19.450$, significance of $\mathrm{F}$ change $\leq 0.001 .{ }^{*} \mathrm{p}<0.05,{ }^{\dagger} \mathrm{p}<0.01,{ }^{\ddagger} \mathrm{p}<0.001$. Duration unit: minute. SE: standard error

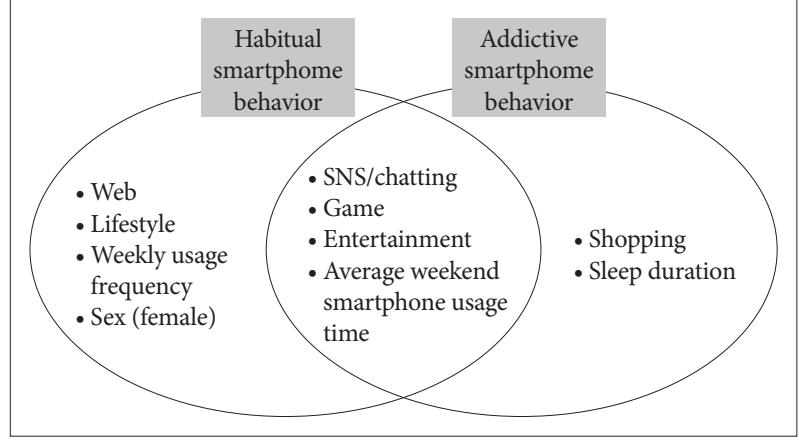

Figure 2. Predictors of habitual and addictive SB.

Facebook, YouTube, Instagram, KakaoTalk, and Line. Recently, social networking channels such as Facebook and Instagram are not only used for social communication, but also for selfrepresentation or recording users' daily lives, like a part of a diary. In addition, entertainment apps such as YouTube have become a platform widely used not just for fun but also for purposes of obtaining information. This diversification of usage of SNSs and entertainment may be linked to why their use has aspects of both habitual and addictive SB. In other words, it is assumed that these types share not only rewarding elements from the original purpose of use of these apps, such as enjoyment, but also habitual elements from the extended usage purpose such as managing one's own life. In addition, the average weekend smartphone usage time, not weekday usage time, was also a common predictor. This may be because the majority (about 83\%) of our study participants were office workers or students. However, this result is consistent with other studies among adolescents or adults, which showed that weekend average usage time was a predictor of PSU. ${ }^{37,38}$

Second, we identified the different predictors of habitual and addictive SB.

The predictors of habitual SB, which were not predictors of addictive $\mathrm{SB}$ in terms of content types of smartphone use were web and lifestyle apps. The web apps category consisted of web browsers, while the lifestyle app category consisted of phone calls, text messages, e-mail addresses, diaries, real estate, deliveries, and delivery tracking. The web and lifestyle apps are closely related to everyday life and currently accessed them more from smartphones than from any other types of device because of the ubiquitous accessibility nature of smartphones. A previous study reported that checking e-mails or messages was related to the strongest habitual pattern and that these kinds of brief-checking behaviors may increase overall smartphone use. ${ }^{4}$ In addition, the frequency of the weekly smartphone use 
was another predictor of habitual SB. Considering that the definition of habitual SB implies the repetitive use of a smartphone, it is natural that habitual SB was associated with the weekly usage frequency. On average, people check their smartphones 46 times per day ${ }^{39}$ A previous study revealed that the frequency of smartphone use was as important as the amount of usage to identify PSU. ${ }^{33}$

Furthermore, we found that the female sex was a predictor of habitual SB although we designed our study to control sex. In other words, women engage in more habitual SB than men do. Previous studies reported that sex is a critical factor in $\mathrm{PSU}^{40,41}$ and there was a gender difference in the way a smartphone was used. ${ }^{3}$ This may suggest that the predictors of smartphone addiction previously identified may be more related to habitual SB in women when we evaluate PSU based on the habitual and addictive SB concepts. Therefore, in order to understand and manage people who have PSU, there is a need to consider both the habitual and addictive SB aspects.

The only predictor of addictive SB that was not a predictor of habitual SB in terms of application type was shopping apps. Previous studies suggested that pathological online buying shares several key characteristics with behavioral addictions and it is considered a form of Internet addiction. ${ }^{42}$ In addition, an increase in craving was observed after online shopping picture exposure and this craving reaction correlated with pathological buying behavior. ${ }^{42}$ Over the past decade, the shopping process has been altered and shopping enabled via the smartphone introduces new features to the shopping experience. This current smartphone-based shopping experience featuring a variety of visual product advertisement, convenience, and ease of use even in the overseas store may trigger craving and lead to addictive behavior.

Finally, we found an association between sleep duration and addictive SB. Consistent with our findings, many studies have reported a positive association between sleep deprivation and PSU or between poor sleep quality and PSU. ${ }^{18,22,43}$ Sleep problems such as bedtime phone usage before sleep may not only contribute to the onset of PSU but was shown to act as a prognostic factor for PSU recover. ${ }^{44}$ These results support the hypothesis that smartphone use affects sleep patterns, for example, through light stimulation, which would therefore explain the addictive SB increasing sleep deprivation. Furthermore, sleep plays a significant role in mental health; thus, many studies have focused on sleep as a behavioral marker in mental health. ${ }^{19,26,45,46}$ Therefore, there is a need to carefully monitor and manage sleep to predict and prevent addictive SB.

Overall, the present study showed the presence of different predictors of habitual and addictive SB in PSU depending on the content types of smartphone use, smartphone usage pattern, and sleep duration. However, our findings need to be in- terpreted cautiously because PSU cannot be explained by either habitual SB or addictive SB, just like habit formation is partly involved in the mechanism of addiction but habitual action itself does not cover all addictions in terms of sensitization or negative reinforcement. ${ }^{47,48}$ Therefore, we should consider both aspects and their interaction when approaching PSU.

Nevertheless, the current study is significant. The study proposes that there are habitual and addictive SB aspects in PSU and clarifies which types of smartphone use are related to PSU in the habitual and addictive SB aspects. The results show that the types of productivity enhancement, such as e-mail, and information seeking, such as browsing the news, are related more with habitual SB, while the types of consumption and buying, such as shopping are more related with addictive SB. The types of social information and relationships such as social network, gaming, and entertainment (e.g., viewing movies) are related to both habitual and addictive SB. These results suggest that the categorization with a strong association between stimuli (e.g., e-mail alarm or headlines) and response (e.g., checking) occurs in habitual SB and that the maladaptive and aberrant recruitment of habit process leads to PSU. ${ }^{48,49}$ Whereas the categorization with an association between action (e.g., buying) and outcome (e.g., obtaining rewards or avoiding unpleasant states) has more reinforcing effects and this feature can be related to addictive behavior. ${ }^{48}$ In addition, the categorization with a variety of functions may have both habitual and addictive aspects depending on the users' purpose.

We developed the smartphone addiction risk rating score for a smartphone addiction management application based on habitual SB and addictive SB. ${ }^{50}$ In this app, users periodically respond to related questionnaires of habitual SB and addictive SB. It calculates the smartphone addiction risk rating score and provides an interventions based on the risk score. In addition, In the current app, it is possible to calculate the users' habitual SB score and addictive SB score by using app category usage, weekly usage frequency, sex, weekend usage time, and sleep duration reported by users. We derive the score using the regression equation derived from the study.

In future research, we intend to collect actual usage by app category usage, weekly usage frequency, weekend usage time, and sleep duration through updated app. By collecting the actual data, it is possible to calculate the habitual SB score and addictive SB score without users' response of questionnaires. We can provide interventions for each based on the derived scores. Currently, the smartphone management app has been developed as the first version. In the future, our results will be verified with actual data.

The limitations of this study and suggestions for future studies are as follows. First, we used smartphone usage data from a self-reporting questionnaire. Some studies have reported that 
respondents' estimates of their smartphone use do not necessarily relate to actual use. ${ }^{51}$ Moreover, there was time distortion, where self-reporting smartphone use time was significantly lower than the recorded total smartphone use time via the app ${ }^{52}$ therefore, the studies recommended using objective usage measurements to predict behavior. ${ }^{53}$ In line with these results, future research can use real smartphone usage as sensing data from mobile devices and compare the differences between self-reporting estimates and actual use. Second, we used only the content types of smartphone use, smartphone usage patterns, and sleep duration as independent variables. Previous studies have demonstrated psychological predictors such as depressive symptoms and anxiety in PSU ${ }^{10}$ and process smartphone usage pattern mediated relationships between anxiety and PSU. ${ }^{14}$ Therefore, future research can add psychiatric factors, such as depression, symptoms of attention deficit hyperactivity disorder (ADHD), and anxiety. ${ }^{54}$ Third, we used only six categories of smartphone apps - Google Store has 35 categories of apps. Future research can use diverse and subdivided app categories. Fourth, habitual and addictive SB are meaningful concepts in PSU, but there was no cutoff in the measurement for both types of SB used in the present study. If there is a cutoff value, future research can perform different analyses, such as logistic regression.

The present study suggests that there is a need to consider the habitual and addictive SB aspects to evaluate PSU and that habitual and addictive SB have not only similar features but also different features with respect to the content types of smartphone usage. In addition, these common and different predictors, including using apps and sleep duration, can be used to develop monitoring and prevention services for PSU. Our findings may also be able to take a new approach to future investigations about PSU.

\section{Acknowledgments}

This work was supported by a National Research Foundation of Korea (NRF) grant funded by the Korean government (MSIT) (NRF2018R1C1B6007750).

\section{Conflicts of Interest}

The authors have no potential conflicts of interest to disclose.

\section{Author Contributions}

Conceptualization: Mi Jung Rho. Data curation: Jihwan Park. Formal analysis: Jihwan Park. Funding acquisition: Mi Jung Rho. Investigation: Mi Jung Rho. Methodology: Mi Jung Rho, Jihwan Park. Project administration: Mi Jung Rho. Resources: Mi Jung Rho. Software: Jihwan Park. Supervision: Mi Jung Rho. Validation: Jo-Eun Jeong. Visualization: Jihwan Park. Writing_original draft: Jihwan Park, Mi Jung Rho. Writing_review \& editing: Mi Jung Rho, Jo-Eun Jeong.

\section{ORCID iDs}

\section{Jihwan Park}

Jo-Eun Jeong https://orcid.org/0000-0002-4027-1038

https://orcid.org/0000-0002-4200-278X
Mi Jung Rho

https://orcid.org/0000-0002-9862-0122

\section{REFERENCES}

1. Billieux J, Maurage P, Lopez-Fernandez O, Kuss DJ, Griffiths MD. Can disordered mobile phone use be considered a behavioral addiction? An update on current evidence and a comprehensive model for Future research. Curr Addict Rep 2015;2:156-162.

2. Ministry of Science and ICT NIA. 2019 The survey on smartphone overdenpendence. NIA, 2020, p.8-9.

3. Van Deursen AJ, Bolle CL, Hegner SM, Kommers PA. Modeling habitual and addictive smartphone behavior: the role of smartphone usage types, emotional intelligence, social stress, self-regulation, age, and gender. Comput Human Behav 2015;45:411-420.

4. Oulasvirta A, Rattenbury T, Ma L, Raita E. Habits make smartphone use more pervasive. Pers Ubiquit Comput 2012;16:105-114.

5. Jog MS, Kubota Y, Connolly CI, Hillegaart V, Graybiel AM. Building neural representations of habits. Science 1999;286:1745-1749.

6. Everitt BJ, Robbins TW. Neural systems of reinforcement for drug addiction: from actions to habits to compulsion. Nat Neurosci 2005;8: 1481-1489.

7. Kalivas PW, O'Brien C. Drug addiction as a pathology of staged neuroplasticity. Neuropsychopharmacology 2008;33:166-180.

8. Canales JJ. Stimulant-induced adaptations in neostriatal matrix and striosome systems: transiting from instrumental responding to habitual behavior in drug addiction. Neurobiol Learn Mem 2005;83:93-103.

9. Kalivas PW. Addiction as a pathology in prefrontal cortical regulation of corticostriatal habit circuitry. Neurotox Res 2008;14:185-189.

10. Ha JH, Chin B, Park DH, Ryu SH, Yu J. Characteristics of excessive cellular phone use in Korean adolescents. CyberPsychol Behav 2008; 11:783-784

11. Bianchi A, Phillips JG. Psychological predictors of problem mobile phone use. CyberPsychol Behav 2005;8:39-51.

12. Wu AM, Cheung VI, Ku L, Hung EP. Psychological risk factors of addiction to social networking sites among Chinese smartphone users. J Behav Addict 2013;2:160-166.

13. Lopez-Fernandez O, Honrubia-Serrano L, Freixa-Blanxart M, Gibson W. Prevalence of problematic mobile phone use in British adolescents. Cyberpsychol Behav Soc Network 2013;17:91-98.

14. Elhai JD, Levine JC, Dvorak RD, Hall BJ. Non-social features of smartphone use are most related to depression, anxiety and problematic smartphone use. Comput Human Behav 2017;69:75-82.

15. Limayenm M, Hirt SG, Cheung CM. Habit in the context of IS continuance: theory extension and scale development. ECIS 2003 Proceedings 2003; 90.

16. Bianchi A, Phillips JG. Psychological predictors of problem mobile phone use. Cyberpsychol Behav 2005;8:39-51.

17. Lee SJ, Rho M, Yook I, Park SH, Jang KS, Park BJ, et al. Design, development and implementation of a smartphone overdependence management system for the self-control of smart devices. Appl Sci 2016;6: 440 .

18. Demirci K, Akgönül M, Akpinar A. Relationship of smartphone use severity with sleep quality, depression, and anxiety in university students. J Behav Addict 2015;4:85-92.

19. Alimoradi Z, Lin C-Y, Broström A, Bülow PH, Bajalan Z, Griffiths $\mathrm{MD}$, et al. Internet addiction and sleep problems: a systematic review and meta-analysis. Sleep Med Rev 2019;47:51-61.

20. Han HH. The relationship among smartphone addiction, lack of sleep and sleeping hours of university students. J Converg Inf Technol 2019; 9:213-219.

21. Heo JY, Kim SH, Han MA, Ahn YJ. Correlation between smartphone addiction and quality of sleep among university school students, graduate students. J Kor Institute Electron Commun Sci 2015;10:737-748.

22. Randler C, Wolfgang L, Matt K, Demirhan E, Horzum MB, Beşoluk Ş. Smartphone addiction proneness in relation to sleep and morning- 
ness-eveningness in German adolescents. J Behav Addict 2016;5:465473.

23. Choi D. Physical activity level, sleep quality, attention control and selfregulated learning along to smartphone addiction among college students. J Kor Acad Indust Cooper Soc 2015;16:429-437.

24. Abdullah S, Matthews M, Murnane EL, Gay G, Choudhury T. Towards circadian computing: early to bed and early to rise makes some of us unhealthy and sleep deprived. Proceedings of the 2014 ACM international joint conference on pervasive and ubiquitous computing: ACM; 2014, p.673-684.

25. Sivertsen B, Krokstad S, Øverland S, Mykletun A. The epidemiology of insomnia: Associations with physical and mental health.: the HUNT-2 study. JPsychosom Res 2009;67:109-116.

26. Wang R, Chen F, Chen Z, Li T, Harari G, Tignor S, et al. StudentLife: assessing mental health, academic performance and behavioral trends of college students using smartphones. Proceedings of the 2014 ACM international joint conference on pervasive and ubiquitous computing: ACM; 2014, p.3-14.

27. Takao M, Takahashi S, Kitamura M. Addictive personality and problematic mobile phone use. Cyberpsychol Behav 2009;12:501-507.

28. Kardefelt-Winther D. Problematizing excessive online gaming and its psychological predictors. Comput Human Behav 2014;31:118-122.

29. Kneer J, Glock S. Escaping in digital games: The relationship between playing motives and addictive tendencies in males. Comput Human Behav 2013;29:1415-1420.

30. Spekman MLC, Konijn EA, Roelofsma PHMP, Griffiths MD. Gaming addiction, definition and measurement: a large-scale empirical study. Comput Human Behav 2013;29:2150-2155.

31. Lee H, Ahn H, Nguyen TG, Choi SW, Kim DJ. Comparing the self-report and measured smartphone usage of college students: a pilot study. Psychiatry Investig 2017;14:198-204.

32. Jeong SH, Kim H, Yum JY, Hwang Y. What type of content are smartphone users addicted to?: SNS vs. games. Comput Human Behav 2016;54:10-17.

33. Bae S-M. The relationship between the type of smartphone use and smartphone dependence of Korean adolescents: National survey study. Child Youth Serv Rev 2017;81:207-211.

34. Tone HJ, Zhao HR, Yan WS. The attraction of online games: an important factor for internet addiction. Comput Human Behav 2014;30:321327.

35. Lopez-Fernandez O, Honrubia-Serrano ML, Baguley T, Griffiths MD. Pathological video game playing in Spanish and British adolescents: Towards the exploration of Internet Gaming Disorder symptomatology. Comput Human Behav 2014;41:304-312.

36. Lopez-Fernandez O, Freixa-Blanxart M, Honrubia-Serrano ML. The problematic internet entertainment use scale for adolescents: prevalence of problem internet use in Spanish high school students. Cyberpsychol Behav Soc Network 2012;16:108-118.

37. Kim Y, Jeong JE, Cho H, Jung DJ, Kwak M, Rho MJ, et al. Personality factors predicting smartphone addiction predisposition: Behavioral inhibition and activation systems, impulsivity, and self-control. PLoS one 2016;11:e0159788.
38. Hwang Y, Park N. Is smartphone addiction comparable between adolescents and adults? Examination of the degree of smartphone use, type of smartphone activities, and addiction levels among adolescents and adults. Examination of the Degree of Smartphone Use, Type of Smartphone Activities, and Addiction Levels Among Adolescents and Adults (June 30, 2017) International Telecommunications Policy Review 2017;24.

39. Economist T. Planet of the phones. J Economist 2015:9.

40. Yang SY, Lin CY, Huang YC, Chang JH. Gender differences in the association of smartphone use with the vitality and mental health of adolescent students. J Am College Health 2018;66:693-701.

41. Chen B, Liu F, Ding S, Ying X, Wang L, Wen Y. Gender differences in factors associated with smartphone addiction: a cross-sectional study among medical college students. BMC Psychiatry 2017;17:341.

42. Trotzke P, Starcke K, M?ller A, Brand M. Pathological buying online as a specific form of internet addiction: a model-based experimental investigation. PLoS One 2015;10:e140296.

43. Kim SH, Min JW, Park BK. The effect of smartphone addiction and stress on sleep quality among university students. J Korea Acad Industr Coop Soc 2019;20:112-120.

44. Lee SY, Lee HK, Choi JS, Bang SY, Park MH, Jung KI, et al. The Matthew effect in recovery from smartphone addiction in a 6-month longitudinal study of children and adolescents. Int J Environ Res Public Health 2020;17:4751.

45. Mohr DC, Zhang M, Schueller SM. Personal sensing: understanding mental health using ubiquitous sensors and machine learning. Annu Rev Clin Psychol 2017;13:23-47.

46. Sami H, Danielle L, Lihi D, Elena S. The effect of sleep disturbances and internet addiction on suicidal ideation among adolescents in the presence of depressive symptoms. Psychiatry Res 2018;267:327-332.

47. Koob GF, Le Moal M. Drug addiction, dysregulation of reward, and allostasis. Neuropsychopharmacology 2001;24:97-129.

48. Schwabe L, Dickinson A, Wolf OT. Stress, habits, and drug addiction: a psychoneuroendocrinological perspective. Exp Clin Psychopharmacol 2011;19:53-63.

49. Dickinson A. Actions and habits: the development of behavioural autonomy. Phil Trans R Soc Lond B 1985;308:67-78.

50. Park J, Jeong JE, Park SY, Rho MJ. Development of the smartphone addiction risk rating score for a smartphone addiction management application. Front Public Health 2020;8:485.

51. Andrews S, Ellis DA, Shaw H, Piwek L. Beyond self-report: tools to compare estimated and real-world smartphone use. PLos One 2015; 10:e0139004.

52. Lin YH, Lin YC, Lee YH, Lin PH, Lin SH, Chang LR, et al. Time distortion associated with smartphone addiction: identifying smartphone addiction via a mobile application (App). J Psychiatr Res 2015;65:139145.

53. Ellis DA, Davidson BI, Shaw H, Geyer K. Do smartphone usage scales predict behavior? Int J Human Comput Stud 2019;130:86-92.

54. Rho MJ, Park J, Na E, Jeong JE, Kim JK, Kim DJ, et al. Types of problematic smartphone use based on psychiatric symptoms. Psychiatr Res 2019;275:46-52. 